\title{
O CONCEITO DE DESERTIFICAÇÃO: CONSTRUÇÃO HISTÓRICA, CRÍTICAS E POTENCIALIDADES
}

\section{The desertification concept: historic construction, critics and potentials}

\author{
Lucas Lopes Barreto ${ }^{1}$ http://orcid.org/0000-0001-7569-9184 \\ Ana Rosa Viana Cezário² http://orcid.org/0000-0001-9214-7381 \\ Vládia Pinto Vidal de Oliveira ${ }^{3}$ http://orcid.org/0000-0001-7756-9009
}

\footnotetext{
${ }^{1}$ Doutor em Geografia - Universidade Federal do Ceará - Professor Secretaria da Educação do Estado do Ceará. E-mail: lucasbarreto7@yahoo.com

${ }^{2}$ Mestra em Geografia - Universidade Federal do Ceará - Professora Secretaria da Educação do Estado do Ceará. E-mail: anarosavianageo@ hotmail.com

${ }^{3}$ Doutora em Geografia. Professora - Universidade Federal do Ceará. E-mail: vladia.ufc@gmail.com
}

\begin{abstract}
Resumo
A desertificação é um dos problemas ambientais que refletem como a sociedade age de modo predatório e insustentável sobre a natureza, alterando os aspectos naturais, sociais e econômicos da paisagem, mostrando como são necessárias ações que contribuam para melhor planejamento e gestão dos recursos naturais. O presente trabalho tem o objetivo de realizar uma análise sobre o conceito de desertificação, mostrando o contexto de sua formulação, críticas e potencialidades perante a temática ambiental. A metodologia é composta por uma análise dos principais marcos históricos da desertificação, que fazem este problema ambiental tão distinto no globo. Pode-se concluir que conceito de desertificação contribui para análise ambiental por mostrar a localização do desenvolvimento deste problema e seus causadores, possibilitando ações de prevenção, retroação e recuperação de áreas degradadas.
\end{abstract}

Palavras-chave: desertificação, conceito, análise ambiental.

\begin{abstract}
Desertification is one of the environmental problems that reflect how society acts in a predatory and unsustainable way over nature, altering the natural, social and economic aspects of the landscape, showing the necessity of actions that contribute to better planning and management of natural resources. This paper aims to perform an analysis on the concept of desertification, showing the context of its formulation, criticism and potentialities regarding the environmental theme. The methodology consists of an analysis of the main landmarks of desertification, which make this environmental problem so distinct on the globe. It can be concluded that the concept of desertification contributes to environmental analysis by showing the location of the development of this problem and its causes, enabling prevention, retroaction and recovery of degraded areas.
\end{abstract}

Keywords: Desertification, concept, environmental analysis. 
O conceito de desertificação: construção histórica, críticas e potencialidades

Lucas Lopes Barreto; Ana Rosa Viana Cesário; Vládia Pinto Vidal de Oliveira

\section{Introdução}

O debate ambiental está presente em vários grupos sociais na atualidade, devido as ações predatórias da humanidade sobre a natureza, que reflete na relação natureza-sociedade desequilibrada, que pode resultar: nas modificações irrevessíveis da paisagem, na transformação dos recursos que seriam renováveis em não-renováveis (NASCIMENTO, 2006), no desmantelamento das atividades econômicas e no aumento das desigualdades sociais.

A academia coopera na discussão ambiental por meio de conceitos, de teorias, de metodologias e de procedimentos que visem novas compreensões, novas análises, novos dados dos problemas ambientais, para que possam fazer novas ações e novas políticas, construindo no melhor planejamento dos recursos naturais.

A desertificação é um dos processos que causa desequílibros entre a natureza e sociedade, pois atinge um terço da superfície emersa, estando em áreas que são responsáveis por $22 \%$ da produção de alimentos no globo (BRASIL, 1998) e afeta diretamente 250 milhões de pessoas (REGO, 2012), mostrando a emergência da análise deste problema ambiental.

O conceito de desertificação no qual esta pesquisa está embasada, é aquele proposto pela "Convenção das Nações Unidas para o combate à desertificação nos países que sofrem seca grave e/ou desertificação, particularmente na África”. Segundo esta convenção:

a) Por desertificação entende-se a degradação da terra nas zonas áridas, semi-áridas e sub-úmidas secas, resultantes de vários fatores, incluindo as variações climáticas e as atividades humanas.

b) Por combate à desertificação entendem-se as atividades que fazem parte do aproveitamento integrado da terra nas zonas áridas, semi-áridas e sub-úmidas secas com vistas ao seu desenvolvimento sustentável, e que têm por objetivo:

I. a prevenção e/ou redução da degradação das terras,

II. a reabilitação de terras parcialmente degradadas, e

III. a recuperação de terras degradadas. (BRASIL, 1998, p.13)

A presente pesquisa visa analisar o conceito de desertificação de Brasil (1998) mostrando o contexto de sua formulação, suas críticas e suas potencialidades.

\section{Contextualização histórica da desertificação.}

O termo desertificação, segundo Matallo Junior (2009) e Rego (2012), teria sido mencionado pela primeira vez por Louis Lavauden, em 1927, e Andre Aubreville, em 1949, popularizou-se o termo. Já Conti (2008) e Nascimento (2006) consideram Andre Aubreville 
como seu precursor a partir do trabalho desenvolvido sobre a degradação feita pelas metrópoles europeias nas ex-colônias africanas, especificamente nas florestas equatoriais, havendo assim transferências culturais, científicas e técnicas europeias, que resultaram no mau uso dos recursos durante 100 a 150 anos.

Portanto, o desmatamento e outras práticas de má utilização dos recursos naturais resultaram em impactos como: o aumento dos processos erosivos e nos ressecamentos dos solos, assim pode-se entender que o uso desse conceito está, desde o início, na atuação predatória da sociedade sobre o meio. Dessa forma, o homem seria um fator muito significante na desertificação. Vale ressaltar que, para Andre Aubreville, esse processo poderia ocorrer em qualquer tipo climático.

Esse problema toma uma discussão em âmbito global com dois marcos: o Dust Bowl e a seca ocorrida em Sahel no fim da década 60 do século passado (MATALLO JUNIOR, 1999; NASCIMENTO, 2006; REGO, 2012).

O primeiro marco foi o fenômeno Dust Bowl, uma seca entre 1934 a 1936 que atingiu o meio oeste norte-americano, atingindo os Estados de Oklahoma, Kansas, Novo México e Colorado. Rego (2012) aponta que uma das causas desse fenômeno foi a modernização da produção de trigo após a Primeira Guerra Mundial. As terras que eram utilizadas para pastagem foram para a produção de trigo, utilizando os novos maquinários adquiridos. Então, os solos ficaram expostos, devido ao mau uso, e ressecados, também por influência da seca, que facilitou a erosão eólica.

Isso, portanto, resultou em mais de 200 tempestades de areias, os ventos possuíam velocidades inferiores a 120 milhas por hora e com redemoinhos acima de 6 metros de altura, havendo a formação de sucos de erosão longos e retos devido ao solo desprotegido vinculado à intensa prática agrícola (MACEDO, 2007), o que causou impactos na disponibilidade hídrica, afetando os principais ecossistemas locais, potencializando os problemas ambientais, e, consequentemente, os aspectos socioeconômicos (MATALLO JUNIOR, 2001; NASCIMENTO, 2006).

Segundo Grainger (1982), a grandiosidade deste fenômeno foi a criação de uma nuvem de poeira que resultou em uma escuridão equivalente ao eclipse solar em algumas cidades como Nova York e Washington. Esse fenômeno alertou a comunidade científica a entender ainda mais as dinâmicas das paisagens das terras secas e os usos feitos destas.

O segundo marco ocorreu entre 1968 e 1973, no continente africano, especificamente na região do Sahel. Nessa região, ocorreu uma severa estiagem que impactou nos âmbitos ambientais, econômicos e sociais (MATALLO JUNIOR, 1999). Dantas (2005) ainda salienta 
que, entre 1974 até 1985, a seca na região não foi tão extrema, porém os índices pluviométricos também foram abaixo do normal.

Segundo Nimer (1988), essa área sofreu uma mudança na sua produção agrícola com a chegada dos franceses que retiraram a produção de subsistência para implantar as plantações de algodão e amendoim para atender o mercado externo. Essa mudança trouxe implicações sobre os próprios solos dessa região, pois, segundo esse autor, estes já não possuíam grande fertilidade, porque a cultura do algodão, de modo intenso e com técnicas modernas, diminuiu a camada de húmus juntamente às condições de precipitação escassas e irregulares, tornando os solos estéreis. Como os solos não proporcionavam uma grande produção agrícola, a solução foi incorporar novas terras. Com isso, houve maior desmatamento, agravando ainda mais o quadro já existente (MATALLO JUNIOR, 1999).

Uma demonstração desse impacto no âmbito econômico foi a queda da produtividade das áreas afetadas: o Norte do Saara, Tunísia e Marrocos perderam, em 15 anos, 61\% da produtividade (MATALLO JUNIOR, 1999). O fenômeno do Sahel mostrou uma das principais consequências da degradação ambiental nas terras secas: a pobreza, onde afetou um rebanho de aproximadamente 25 milhões e 6 milhões de pessoas (CONTI, 2008), dentre essas, estima-se que 200 mil foram a óbito, principalmente crianças que viviam em condições de higiene e de alimentação miseráveis (NASCIMENTO, 2006).

Devido à gravidade do ocorrido na África, isso criou um alarde sobre esta problemática para a sociedade. As conferências coordenadas pela Organização das Nações Unidas (ONU) ocorridas em Estocolmo, em 1972, e em Nairóbi, em 1977, são exemplos de como se iniciou uma discussão de escala global e de caráter político, mostrando que seriam necessárias maiores articulações na sociedade para entender e retroadir os processos de degradação do meio ambiente. Foi em 1977, que a desertificação foi tratada de modo interdisciplinar (CONTI, 2008; NASCIMENTO, 2006).

Devido à gravidade do ocorrido na África, criam-se mitos sobre a desertificação. Nimer (1988) elenca estes: o mito dos alimentos, o mito da pouca quantidade de terra para agricultura, o mito do desemprego nas áreas rurais e o mito da superpopulação, que mostram que o entendimento da desertificação e suas consequências podem ser analisados de modo equivocado.

O mito dos alimentos refere-se à quantidade de alimentos que não seria suficiente para atender a população mundial como se a fome fosse causada apenas pela desertificação, mas, segundo a Organização das Nações Unidas para a Agricultura e Alimentação (FAO), em 
2009, havia mais de um bilhão de pessoas passando fome no globo, apesar de, no ano anterior, haver recorde mundial da safra de grãos (REGO, 2012).

Nimer (1988) diz que é produzido 1 quilo de alimento por pessoa, quantidade superior à quantidade de alimentos consumida pela população europeia, população essa que pouco sofre com desnutrição. Para o combate aos problemas da produção de alimentos, os países desenvolvidos incentivaram os países em desenvolvimento à modernização da agricultura através da Revolução Verde (ANDRADES, GANIMI, 2007), que contribui para avanços das empresas multinacionais, para o desenvolvimento de suas tecnologias e para o mercado, padronizando o consumo, pois as sementes e os produtos não são nativos, alterando as condições ecológicas locais. Essa revolução, que deveria resolver a fome mundial, ocasionou a desvalorização das culturas tradicionais, o aumento da erosão dos solos e a erosão genética dos produtos agropecuários.

O mito da pouca quantidade de terra para agricultura diz que a baixa produção agrícola está associada com poucas terras agricultáveis em associação a ação da desertificação, portanto haveria a necessidade de ampliação da fronteira agrícola, mas isso contribuiria para maior degradação dos solos, pois os latifúndios não são os responsáveis pela produção de alimentos da população, essa função vincula-se aos minifúndios (OLIVEIRA, 1996).

O mito do desemprego nas áreas rurais diz que a atividade agrícola ofereceria poucas oportunidades de emprego, fato que acentuaria a pobreza que foi causada pela desertificação, havendo a necessidade de se industrializar para a criação de novos empregos para conter a miséria. Porém, a pouca quantidade de emprego no campo está na própria estrutura fundiária e na modernização da agricultura (OLIVEIRA, 1996).

Outro detalhe encontra-se no processo de industrialização. Com o desenvolvimento tecnológico, não se faz necessária a grande quantidade de mão-de-obra sem especialização, intensificando o desemprego e a pobreza.

O mito da superpopulação diz que a escassez de alimentos ocorreria futuramente devido à alta natalidade, mas, nesse pensamento, a sociedade aparece com o mesmo padrão de consumo. Isso não é verdade, pois o modo de consumo de uma família de baixo poder aquisitivo que reside no interior do Nordeste brasileiro é bem inferior à de um cidadão norteamericano, de alto poder aquisitivo, que reside em Nova York. A demanda de recursos naturais cresce com a quantidade de pessoas, mas a questão não está apenas na quantidade de pessoas que consomem, mas principalmente no modo com estas consomem. 
Vale ressaltar que o trabalho de Nimer (1988) sobre os mitos da desertificação foi escrito nos anos 80 do século passado, mas ainda está bem presente no contexto atual, mostrando quanto compreensão da desertificação não é tão clara.

Como a desertificação é um problema que atinge diversos âmbitos, este também está nos meios midiáticos, mas os discursos existentes entre a mídia e a academia, por muitas vezes, não são os mesmos, o que causa equívocos na compreensão dos processos e conceitos existentes.

Mendonça (1998) comenta que isso acontece com os temas vinculados ao meio ambiente, onde há popularização, mas também podem ocorrer algumas banalizações. Isso ocorre com processo de desertificação, mas, para compreender este processo, é necessário abordar dois conceitos que estão vinculados na construção epistemológica e nas políticas públicas da desertificação, que são: deserto e seca.

\section{Desertificação e Deserto}

Os conceitos de desertificação e deserto estão entrelaçados. Nota-se isso na seca ocorrida em Sahel, na década de 60, sendo esta uma região que bordeja o Deserto do Saara. Por isso, associou-se a desertificação como o processo de expansão dos desertos. Como Guerra e Guerra (2008) conceituam:

Processo de desertificação indica o ressecamento climático, que pode ocorrer por períodos longos, ocorrendo erosão do solo, pela ação do escoamento superficial, em decorrência do desmatamento. A desertificação indica interação de fenômenos, que propiciam a transformação de determinadas áreas em desertos. (GUERRA, GUERRA, 2008 p.196)

Esses autores colocam como o ressecamento seria uma evidência do processo da desertificação, essa degradação seria em função das ações sociais (o desmatamento) e que resultaria em um deserto. Nimer (1980) explica que o desmatamento altera no equilíbrio ecológico, mas acha um exagero que este possa mudar o clima regional.

Segundo Retallack (1991), o processo de desertificação desestabiliza a paisagem, podendo desnudar os solos e havendo a criação de campos de dunas, atribuindo a criação de desertos como etapa final. Então, a paisagem desértica foi modelada pela desertificação? Se sim, foi por atuação antrópica, natural ou por ambas?

Buscando explicar essas questões, Nascimento (2006) e Nimer (1980, 1988) mostram, pela própria etimologia, como essas palavras contribuem para alguns equívocos. A palavra deserto está associada a vazio em russo e em árabe; a pouca água e a estranho em chinês; e a 
lugar abandonado em português, em francês, em espanhol e em inglês (NIMER, 1980, 1988); enquanto que desertificação, vindo da forma latina deserta facere, significa fazer ou fabricar um deserto (NASCIMENTO, 2006). Logo, a partir da própria constituição da palavra, pode-se considerar que a formação de deserto é resultante de ações sociais.

Sampaio et al. (2003) e Nimer (1988) comentam a estrutura da palavra "desertificação", dando a entender que esse processo resultaria na formação de um deserto, pois, nas primeiras publicações da temática, esse termo estava vinculado às áreas de expansão do Saara.

Os desertos quentes são áreas da superfície terrestre que possuem temperaturas elevadas, com clima árido e com precipitação anual inferior a $250 \mathrm{~mm}$. Com isso, a vazão das drenagens é intermitente e efêmera, e as ações do intemperismo físico e a erosão eólica são mais atuantes. Como as chuvas são escassas e concentradas em poucos meses, há pouca umidade no ar, facilitando a penetração dos raios solares nos solos, diferentemente do que ocorre em ambiente úmido, onde as chuvas dissolvem os minerais na superfície. Em ambientes desérticos, a evapotranspiração contribui para um acúmulo de minerais, como sódio e potássio na superfície dos solos (CONTI, 2008; NIMER, 1980, 1988).

A vegetação é esparsa, com espécies xerófilas, adaptadas às condições de escassez: aquelas que só desenvolvem como baixa quantidade de umidade; essas vegetações têm a capacidade de armazenar água, o exemplo significativo são os cactos e arbustos de desertos. Assim, esse ecossistema há clímax ecológico, e são áreas de vazios demográficos (CONTI, 2008; NIMER, 1980, 1988).

Nimer (1988) explica que os desertos em sua constituição e manutenção estariam diretamente associados com a escassez de chuvas. As condições de aridez nos desertos são apontadas a seguir (Quadro 1).

Quadro 1: Condições de aridez nos desertos

\begin{tabular}{|c|l|}
\hline Condições & \\
\hline $\begin{array}{c}\text { As altas pressões de } \\
\text { anticiclone tropical e } \\
\text { subtropical }\end{array}$ & $\begin{array}{l}\text { É a causa mais relevante à existência desse ecossistema, estando vinculado com } \\
\text { a circulação atmosférica, e pouco com os fatores geográficos, com exceção da } \\
\text { forma da Terra. Essas áreas são as de latitude 30 } 0^{\circ} \text { onde estão os desertos do } \\
\text { Saara e Australiano. }\end{array}$ \\
\hline $\begin{array}{c}\text { O posicionamento } \\
\text { físico-geográfico }\end{array}$ & $\begin{array}{l}\text { É vinculado à relação geomorfologia e clima, onde o relevo contribui para que } \\
\text { as precipitações sejam distintas de uma mesma região, formando áreas de } \\
\text { sotavento e barlavento, o primeiro possui menores precipitações do que o } \\
\text { segundo. O deserto do sudoeste dos Estados Unidos possui a atuação desse } \\
\text { fator mais evidente. }\end{array}$ \\
\hline $\begin{array}{c}\text { As altas latitudes } \\
\text { É causa mais evidente nos desertos de Takla Makan e Gobi. } \\
\text { oceânicas frias }\end{array}$ & $\begin{array}{l}\text { É causa bem evidente no deserto do Atacama, que contribuem para diminuição } \\
\text { de evaporação e umidade do ar. }\end{array}$ \\
\hline
\end{tabular}

Fonte: adaptado de Nimer (1988) 
Esses fatores, juntamente às características que o constituem, mostram que o homem não é responsável na origem de um deserto, pois as causas naturais são predominantes, principalmente o clima regional, e que a desertificação não possui, em seus fatores, apenas de ordem natural. Assim, pode-se entender que o deserto é um ambiente, um ecossistema com dinâmica própria, estando em clímax ecológico, enquanto a desertificação é processo gradativo, havendo um desequilíbrio das trocas de energia e matéria, resultando em uma degradação ambiental.

Esses conceitos têm semelhanças apenas em seus nomes, mas os ambientes têm suas dinâmicas, suas estruturas e suas funções distintas. Enquanto que, em um, o fator natural, principalmente o clima, é predominante na sua instalação e na sua manutenção; no outro, as relações desarmônicas entre natureza e sociedade contribuem para o seu desenvolvimento.

Matallo Junior (2001) salienta que a questão dos desertos e da desertificação pode trazer implicações de como a sociedade civil entende essa problemática das terras secas, pois parte dessa sociedade associa o deserto a uma paisagem de grande quantidade de areia, e considerando a desertificação como a transformação de uma paisagem em deserto, havendo, portanto, incredulidade na atuação desse processo.

Em áreas do Nordeste brasileiro, como os Núcleos de Desertificação cearenses, há paisagens desertificadas em níveis graves, mas que pouco produz areia, assim a sociedade civil pode não repensar sobre as suas práticas predatórias por não enxergar esses sinais das "evidências" da desertificação.

Tratar os desertos como o resultado de processo de degradação ambiental é modo pejorativo de entender este ecossistema, é desvalorizar a potencialidade paisagística, a fauna e a flora e a própria humanidade, pois as antigas civilizações que contribuíram, com seus conhecimentos, para a sociedade atual eram sociedades que viviam em áreas de desertos.

\section{Desertificação e Seca}

Tratando-se das relações entre seca e desertificação, a seca é definida por Conti (2008) como a prolongada falta de chuvas que pode se estender por 2 a 3 anos, sendo este um fenômeno transitório, no qual a relação entre a temperatura e o balanço hídrico do solo é fundamental para déficit hídrico existente.

A seca seria um fenômeno natural no qual as precipitações são abaixo do normal, resultando diretamente no desequilíbrio hídrico e refletindo nos sistemas de produção 
dependentes da terra, ou seja, nas comunidades que retiram sua renda da produção agrícola (SAMPAIO et al. 2003).

Segundo Souza e Oliveira (2002), a seca não se limita às condições pluviométricas adversas, sendo esta o problema crônico no Nordeste brasileiro de clima semiárido, pois esse problema tem impactos negativos nos quadros ambientais, sociais e econômicos. Esses autores ainda dizem que essa característica de irregularidades nas precipitações é típica do clima semiárido, o que dificulta ações, planejamentos e políticas públicas devido à incerteza das chuvas, bem diferentes dos ambientes desérticos e úmidos.

Essa questão da seca e sua atuação não devem ser tratadas como a única justificativa pelo pouco desenvolvimento das áreas atingidas por este fenômeno:

Se a seca é uma terrível realidade, ela não é o principal fator de empobrecimento. Os fatores principais são a estrutura fundiária, creditícia de comercialização, e a inadequação das culturas às condições de solo e clima. De modo especial, o impacto provocado pelas secas se agudiza em função da rentabilidade inexpressiva dos empreendimentos rurais e das deficiências da tecnologia rudimentar adotada (SOUZA, OLIVEIRA, 2002, p.213).

Assim, é evidente que os problemas gerados, como pobreza, fome, miséria entre outros, estão além de serem explicados e entendidos apenas pelas condições climáticas. Esse pensamento de que o clima é o único fator de atraso de desenvolvimento contribui para a naturalização dos problemas ambientais. É claro que a causa da seca é natural, faz parte da dinâmica climática das regiões que esta afeta, porém ações de mau uso proporcionado pela sociedade agravam o fenômeno.

Segundo Nimer (1988), a atribuição do clima para atrasos econômicos vem desde o período colonial em várias partes do planeta, e essa perspectiva está bem presente em algumas políticas assistencialistas na atualidade. Souza e Oliveira (2002) explicam que a seca tem seu lado político, pois a situação social de terras improdutivas, analfabetismo e migração contribuem na manutenção do poder político e econômico da região, fazendo um sistema de poder local limitado em algumas famílias e em pequenos grupos sociais. As políticas a serem implantadas são para o favorecimento e o fortalecimento desses grupos locais e resultam em empobrecimento de grande parcela da população.

A seca e a desertificação são processos diferentes, mas se relacionam. A desertificação é um processo cumulativo da degradação ambiental da paisagem, e quando esta se encontra em um nível mais avançado, afeta as condições socioeconômicas, sendo que a sua 
reversibilidade não ocorrerá de modo instantâneo e natural. Dessa forma, o planejamento ambiental é necessário para a retroação, a mitigação e a convivência com a desertificação.

Enquanto, que a seca, por se caracterizar como um fenômeno natural de ocorrência esporádica, em que ocorre a redução da precipitação, não possui um clima específico para sua atuação, mas é um fenômeno reversível, pois depende da disponibilidade hídrica, dependendo da gravidade do processo, mesmo com o período chuvoso, a seca pode deixar marcas na paisagem como diminuição de biodiversidade ou mudanças no uso da terra.

$\mathrm{Na}$ realidade do Nordeste brasileiro, a seca pode potencializar na ação da desertificação. Com isso, a capacidade de regeneração bem peculiar do bioma caatinga diminui drasticamente, assim, mesmo a flora adaptada à aridez não se sustenta devido ao agravamento das condições hidroclimáticas e ao elevado desmatamento. Isso mostra as relações entre desertificação e seca, porém o seu monitoramento, os seus indicadores e as estratégias não são os mesmos (SAMPAIO et al. 2003). A seca exige políticas a curto prazo, enquanto que a desertificação, a longo prazo (REGO, 2012).

\section{Conceito de Desertificação: críticas e potencialidades à questão ambiental.}

O conceito de desertificação de Brasil (1998) possui relevância a questão ambiental, pois identifica onde o processo ocorre e quem são os seus causadores. A localização desse processo é baseada no clima por meio do índice de aridez de Thornthwaite (1841). Esse índice é o resultado do quociente entre precipitação anual com a evapotranspiração anual de uma determinada área, delimitado a seguir (Quadro 2).

Quadro 2: Índice de aridez e desertificação.

\begin{tabular}{|c|c|c|}
\hline CATEGORIA & ÍNDICE DE ARIDEZ & $\begin{array}{c}\text { SUSCEPTIBILIDADE A } \\
\text { DESERTIFICAÇÃ O }\end{array}$ \\
\hline Subúmido úmido & Acima de 0,65 & Não susceptível \\
\hline Subúmido seco & $0,65-0,51$ & Moderada \\
\hline Semiárido & $0,50-0,21$ & Alta \\
\hline Árido & $0,20-0,05$ & Muito alta \\
\hline Hiperárido & Inferior a 0,5 & Muito alta \\
\hline
\end{tabular}

Fonte: Matallo Junior, 1999.

A suscetibilidade, no quadro acima, leva em consideração primordialmente a aridez, e não o processo de desertificação como um todo, pois, como o próprio conceito que este trabalho está embasado mostra a desertificação afeta vários aspectos da paisagem.

Outro ponto abordado no conceito está nas causas da desertificação, estas possuem tanto aspectos naturais como sociais, distanciando da ideia de que desertificação é processo de 
criação de deserto, desnaturalizando-o, e colocando também sobre a sociedade a responsabilidade deste problema ambiental, viabilizando estratégias para mitigação e convivência com esse processo.

Esse conceito, assim como todo conceito, não é unânime, lembrando que há 1000 conceituações de desertificação na literatura (REGO, 2012). O conceito de desertificação de Brasil (1998) possui críticas de Sampaio et al. (2003) e Matallo Junior (2001).

Segundo Sampaio et al. (2003) o conceito de desertificação da ONU possui maior ênfase no intuito econômico do que no ambiental e no social. A questão colocada por esses autores é que se preservariam as paisagens desertificadas, a sua flora e a sua fauna para fins de extração, para que houvesse matéria-prima ao mercado.

A crítica de Sampaio et al. (2003) é compreensível, pois há pouca preservação quando se colocam os fins econômicos acima das questões sociais e ambientais, já que, a exigência do mercado é tamanha, requerendo espécies específicas para atender a sua demanda, assim não haveria a diminuição da degradação.

Segundo Mendonça (1992), a desertificação é degradação tanto dos recursos naturais como das populações residentes, então, é claro que recursos naturais são utilizados para suprir a necessidade da sociedade, mas é necessário entender também que, antes mesmo do surgimento do homo sapiens, a dinâmica natural existia. A preservação e a conservação do meio ambiente devem ser, primeiramente, para a manutenção da vida na Terra, e isso inclui a dinâmica da fauna e da flora e para manutenção da própria sociedade.

Matallo Junior (2001) critica o conceito de desertificação proposto pela Convenção das Nações Unidas nos seguintes aspectos: amplitude conceitual, ausência de métodos universais para avaliar o processo tanto no âmbito ambiental, social e econômico e a falta de "clareza empírica" das diferenças entre desertificação e seca, apenas o último ponto já foi explanado anteriormente.

A amplitude conceitual criticada pelo autor está na falta de um objeto de estudo, mas a desertificação é uma temática da questão ambiental, é um tema transversal por meio do qual deve haver um diálogo entre várias ciências, não necessitando, portanto, de objeto de estudo.

As ausências de métodos universais e de técnicas de mensuração desse processo vinculam-se com o aspecto de amplitude conceitual, refletindo diretamente nas metodologias utilizadas, que o autor chama de "proliferações de métodos".

Em uma pesquisa que tem perspectiva setorial, não há integração entre os elementos que compõe a paisagem, não é possível entender a complexidade da desertificação. Porém em uma pesquisa de perspectiva ambiental, em que se exige a integração dos elementos em uma 
determinada realidade, esta perspectiva conseguiria abarcar os processos e as problemáticas existentes, assim, a análise ambiental é a mais adequada para o entendimento da atuação da desertificação.

Vale ressaltar que a mensuração desse processo ainda é desafio, pois não há um consenso, de quais os indicadores mais adequados para se avaliar a atuação da desertificação por todo o globo. As críticas feitas por Matallo Junior (2001) e o Sampaio et al., (2003) fazem parte do processo científico.

A desertificação é um problema de âmbito global. Para entender as dinâmicas desses ambientes degradados, seria necessário delimitar onde esse processo aconteceria. $\mathrm{O}$ índice de aridez contribui para que não haja uma generalização exacerbada do processo, pois, caso contrário, qualquer problema ambiental no mundo poderia se enquadrar no processo de desertificação.

Também é necessário entender que o clima e a aridez não são as causas predominantes desse processo, mas que estes são elementos-chaves para delimitação desse problema. Tratando-se de um problema de causa e efeito, que não é simples de delimitar, como os pesquisadores poderiam delimitar esse problema que tem a sua ocorrência em várias partes do Planeta?

Caso não houvesse um elemento-chave para delimitar esse processo, toda área degradada poderia ser considerada como área desertificada, principalmente por ser um problema de escala global, havendo a dificuldade para abarcar as peculiaridades locais existentes. Portanto, como particularizar um problema que se mostra cada vez mais global? Neste conflito entre escalas de análise, que resultou no conceito da ONU (BRASIL, 1998) para a desertificação, sendo este conceito não vago, porém generalizado.

É necessário entender que todo conceito não pode ser engessado, tornando-o inflexível, pois a própria ciência é feita por conflitos, indagações e questionamentos daquilo que está posto, conflitos entre aquilo que se tem como verdade com aquilo que se apresenta para questioná-la. É nesta ação dialética que se tem a construção, a desconstrução e a reconstrução dos conceitos.

\section{Considerações finais}

O presente artigo mostrou como o conceito de desertificação de Brasil (1998) foi relevante para a temática ambiental, contribuindo no entendimento da degradação ambiental das terras de climas áridos, semiáridos e subúmido secos por meio das suas consequências, 
apontadas no seu contexto histórico, e na construção teórica deste problema, que se distingiu dos conceitos de deserto e de seca, além de possilitar ações para análise e práticas de planejamento ambiental.

A desertificação teve status de problema ambiental global após o Dust Bowl e a severa estiagem ocorrida na Região de Sarel, quando se reafimou o quanto a sociedade é danosa à natureza e a ela mesma, necessitando repensar o modo de produção, reafimando as diferentes dimensões (naturais, sociais, econômicas e políticas) que o processo de degradação das terras secas possui.

Os cuidados na análise em ambientes desertificados são necessários para que não se crie mitos equivocados (NILMER, 1988), e que não haja a naturalização, quando propõem como áreas desertificadas resultarão em desertos; ou tratar como um problema temporário, quando se equipara a seca à desertificação.

Por isso, conceito de desertificação de Brasil (1998) é adequado no uso de práticas de planejamento ambiental, pois delimitar quais paisagens podem ocorrer o processo e norteia os seus causadores, colaborando tanto nas questões teóricas quando em ações e políticas, possibilitando a prevenção, a retroação e a recuperação de áreas degradadas.

\section{REFERÊNCIAS}

ANDRADES, T. O.; GANIMI, R.N. Revolução verde e a apropriação capitalista. CES Revista (CES/JF. Impresso), v. 21, p. 43-56, 2007.

BRASIL. Ministério do Meio Ambiente, dos Recursos Hídricos e da Amazônia Legal. Convenção das Nações Unidas de combate a desertificação nos países afetados por seca grave e/ou desertificação, particularmente na Africa. 2.ed. Brasilia: MMA/PNUD/FGEB, 1998.

CONTI, J. B. Conceito de desertificação. Revista Climatologia e Estudos da Paisagem, Rio Claro, v. 3, n. 2, p.39-52, 2008.

DANTAS, C.C. G. Gestão ambiental: um estudo sobre a percepção do problema da desertificação no estado do Rio Grande do Norte. Dissertação de Mestrado apresendada no Programa de Pós-Graduação de Engenharia de Produção da Universidade Federal do Rio Grande do Norte. Natal, 2005. 80p.

GRAINGER, A. Desertification: how people make deserts, how people can stop and why they don't. London: Earthscan Publication Ltd, 1982.

GUERRA, A.T.; GUERRA, A. J. T. Novo Dicionário Geológico-Geomorfológico. $6^{\mathrm{a}}$ Edição. Rio de Janeiro: Bertrand Brasil, 2008. 
MACEDO, M. R. O. B. C. Uma abordagem temática e espectral de áreas passíveis à desertificação na região do Seridó - RN/PB. Dissertação de Mestrado apresendada no Programa de Pós-Graduação em Ciências Geogésicas e Tecnologia da Geoinformação da Universidade Federal do Pernambuco. Recife, 2007. 114p.

MATALLO JUNIOR, H. A desertificação no mundo e no brasil. In: SCHENKEL, C. S; MATALLO JÚNIOR, H. (Orgs.). Desertificação. Brasília: UNESCO, 1999.

MATALLO JUNIOR, H. Indicadores de Desertificação: histórico e perspectivas. Brasília: UNESCO, 2001.

MATAllo JUNIOR, H. Glossário de Termos e Conceitos usados no Contexto da UNCCD. Brasília: MMA, 2009.

MENDONÇA, F. A. Geografia e meio ambiente. $3^{\text {a }}$ Ed. São Paulo: Contexto, 1998.

MENDONÇA, F. A. Desertificação: algumas noções e exemplos de ocorrência no Brasil. Revista Geografia, Londrina, v. 7, p.57-64, 1992.

NASCIMENTO, F. R. Degradação ambiental e desertificação no nordeste brasileiro: o contexto da bacia hidrográfica do rio Acaraú. Tese de Doutorado Mestrado apresendada no Programa de Pós-Graduação em Geografia da Universidade Federal Fluminense. Niterói, 2006. 340p.

NIMER, E. Subsídio ao plano de ação mundial para combater a desertificação - Programa das Nações Unidas para o Meio Ambiente - PNUMA. Revista Brasileira de Geografia. IBGE, v.42, n.2/3, p.612-37, 1980.

NIMER, E. Desertificação: realidade ou mito? Revista Brasileira de Geografia. IBGE, v.50, n.1, p.7-39, 1988.

OLIVEIRA, A. U. Agricultura Brasileira Transformações Recentes. In: ROSS, J. L. S. (Org.). Geografia do Brasil. São Paulo: EDUSP, 1996.

RÊGO, A.H. Os sertões e os desertos: o combate à desertificação e a política externa brasileira. Brasília: FUNAG, 2012.

RETALLACK, G.J. Soils of the past: an introduction to paleopedology. Harper Collins Academic. London, 1991.

SAMPAIO, E. V. B.; YONY, S.; VITAL, T.; ARAÚJO, M. S. B.; SAMPAIO, G. R. Desertificação no Brasil: conceitos, núcleos e tecnologias de recuperação e convivência. Recife: Editora Universitária UFPE, 2003.

SOUZA, J. M. N.; OLIVEIRA, V. P. V. Semi-árido do Nordeste do Brasil e o Fenômeno da Seca. In: José Lugo Hubp. (Org.). Desastres Naturales em América Latina. Mexico: Fondo de cultura Econômica, 2002.

THORNTHWAITE, C. W. Atlas of Climatic Types in the United States. Miscell Publ. No. 421. U.S. Departament of Agriculture, Forest Service, 1941. 